\title{
Numerical Analysis of the Effect of Tunnel Advance Support on Surrounding Rock Stability
}

\author{
Zhitao Ma \\ State Key Laboratory of Mining Disaster \\ Prevention and Control, \\ Shandong University of Science and Technology \\ Qingdao, China \\ mazhitao163@163.com \\ Yongqiang Cui \\ College of Mining and Safety Engineering \\ Shandong University of Science and Technology \\ Qingdao, China \\ 2965403731@QQ.com
}

\author{
Xinpeng Wang \\ College of Mining and Safety Engineering. \\ Shandong University of Science and Technology \\ Qingdao, China \\ xinpeng15@126.com
}

\author{
Yachao Yang \\ College of Mining and Safety Engineering. \\ Shandong University of Science and Technology \\ Qingdao, China \\ 1493802064@QQ.com
}

\begin{abstract}
The purpose of this paper is to study the effect of advance support on the stability of tunnel surrounding rock using the numerical analysis. For this, three different cases, such as without support, pipe shed grouting support, and advance small pipe grouting support were calculated and analyzed. The research shows that: both the pipe shed grouting support and advance small pipe grouting support all have a good effect on the supporting and strengthening of tunnel surrounding rocks. They can effectively control the vault settlement, haunch displacement, ground settlement and reduce the plastic zone distribution during tunnel excavation. In addition, compared with the advance small pipe grouting support, the pipe shed grouting support has better effect on supporting and strengthening surrounding rock of tunnel. The study provides a reference for the actual engineering design of the tunnel.
\end{abstract}

Keywords-advance support, soft rock mass, surrounding rock stability

\section{INTRODUCTION}

With the rapid development of China's transportation infrastructure in recent years, more and more tunnels have been passed through the complex geological environment. The special mechanical properties of soft rock and soft soil can lead to rapid deformation of tunnel and different types of ground disturbance. Therefore, the protection of the soft rock layer has received much attention before and after the tunnel construction. As an important auxiliary support measure, the advance support has been widely applied and studied.

Ahad Ziaei et al. [1] used FLAC3D 5.0 to study the effect of topography on stability of shallow tunnels. XianYang et al. [2] for a single arch long-span subway station using the piperoof pre-construction method studied the surface settlement monitoring results and analyzed the causes of settlement. Fan Honghai [3] used FLAC3D to analyze the supporting effect of pipe roof and double row small pipe. Li Shucai et al. [4] used a combination of field tests and numerical simulations to study the support effect of advanced support in silty clay tunnels. JZ Xiao et al. [5] studied the effect of tunnel support components, topography and geological conditions on the mechanical behavior of long pipe roof during the excavation process of buried-biased road tunnels, and revealed the variation law of the internal force and bending moment distribution of the pipe roof during the excavation. Tai Qimin et al. [6] proposed a method to determine the advance support of tunnels in terms of construction safety evaluation,

choice of advanced support methods, and determination of advanced support parameters for the purpose of reasonably determining the type and range of parameters for advance support. Zhang Weishe et al. [7] analyzed the deformation law of surrounding rock and the extension of plastic zone after tunnel excavation by numerical simulation, and established the prediction formula of surface deformation by using Peck formula and nonlinear fitting method. Hong Kairong et al. [8] carried out simulation analysis of the effect of advanced support on the spatial deformation of soft rock tunnels with respect to two kinds of support and reinforcement measures for the pre-reinforcement of the glass fiber anchors and the support of the pipe roof. Wan Fei et al. [9] carried out relevant experiments on the stress characteristics and schemes of shallow buried water-rich soft surrounding rock tunnels, providing references for the design and construction decision of related projects. Liu wei et al. [10] studied the effect of excavation stress release and seepage on tunnel structure and soil deformation at different stages of overlapping tunnel construction by numerical method, and obtained the law of soil deformation in construction of overlapping tunnels with water-rich strata, and proposed control Formation deformation measures at the same time. Liu Tianyu [11] analyzed the support mechanisms and theories of advancement of small catheters in poor geological tunnels, and carried out a simulation demonstration using the FLAC3D software to advance the reasonable support effect of small catheter technology in tunnel construction. Zhang Xiangdong et al. [12] based on the finite element program of ADINA, performed numerical simulation analysis on the nonlinear deformation of the ground surface caused by tunnel construction under supporting conditions such as unsupported, grouted, pipe roff and pipe grouting reinforcement, and revealed the degree of surface deformation response under different support conditions.

The determination of reasonable support scheme is the key to ensure the safety of tunnel through soft surrounding rock. In order to comprehensively understand and master the advanced support and surrounding rock mechanics and 
instability modes of the tunnel, it is necessary to study the stability of the surrounding rock of the tunnel under different advanced support methods, especially the tunnel stability study and parameter optimization in pipe roof and small pipe supporting. And obtain the mechanical responses of the surrounding rock-support system in the construction of pipe roof and small pipe, such as surface settlement, horizontal convergence, the stress and damage of surrounding rock and supporting structures, etc., which provided reference for actual engineering design.

\section{PROJECT OVERVIEW}

A shallow buried tunnel, which is single-line and singlehole. The width and height of the tunnel section is $8 \mathrm{~m} \times 6.5 \mathrm{~m}$, and the tunnel depth is $10 \mathrm{~m}$. The strata of the tunnel are from top to bottom: mixed (plain), silty clay, sandy clay, strong weathered granite, and weathered granite, the soil physical and mechanical parameters are shown in TABLE 1. The tunnel structure passes through the strong weathered granite layer and the weathered granite layer, and the surrounding rock level is determined as $\mathrm{V}$ level as shown in Fig.1.

TABLE I. PHYSICAL AND MECHANICAL PARAMETERS OF SOIL

\begin{tabular}{|c|c|c|c|c|c|c|}
\hline & $\begin{array}{c}\text { Density } \\
\gamma\left(\mathbf{k N} / \mathbf{m}^{3}\right) \\
\end{array}$ & $\begin{array}{c}\text { Elastic modulus } \\
\text { E(MPa) } \\
\end{array}$ & $\begin{array}{c}\text { Poisson's ratio } \\
\mu\end{array}$ & $\begin{array}{c}\text { Friction angle } \\
\varphi\left({ }^{\circ}\right) \\
\end{array}$ & $\begin{array}{c}\text { Cohesion } \\
\text { C(kPa) } \\
\end{array}$ & $\begin{array}{c}\text { Thickness } \\
\text { (m) }\end{array}$ \\
\hline miscellaneous fill & 17.5 & 10.0 & 0.38 & 15 & 10.0 & 1.4 \\
\hline silty clay & 19.2 & 18.0 & 0.30 & 22 & 27.3 & 3.8 \\
\hline sandy clay & 19.7 & 34.5 & 0.28 & 30 & 34.0 & 1.8 \\
\hline Strongly weathered granite & 22.5 & 160.0 & 0.28 & 35 & 55.5 & 8.0 \\
\hline Medium weathered granite & 24.5 & 600.0 & 0.26 & 40 & 100.0 & 25.5 \\
\hline
\end{tabular}

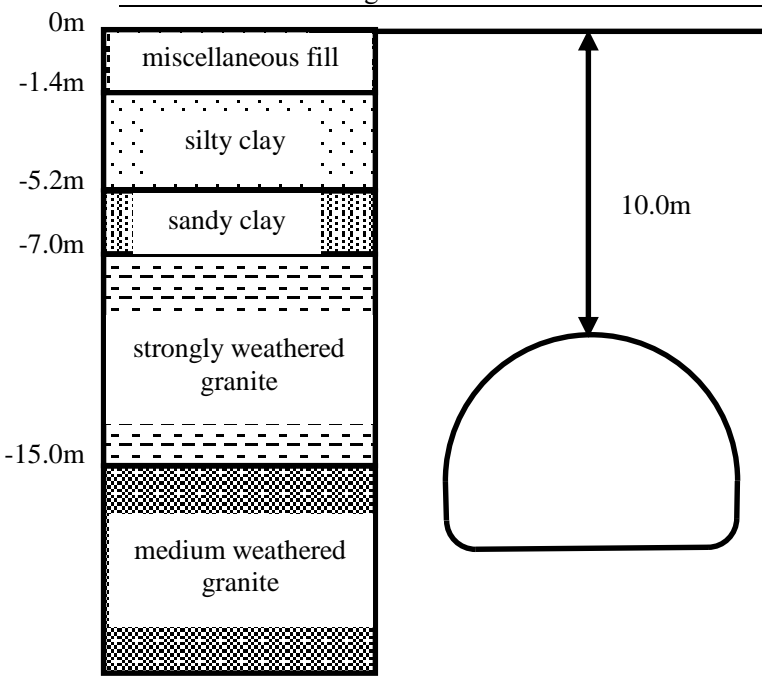

Fig.1 Tunnel depth and surrounding rock distribution

Advance support measures: $\Phi 76$ lead pipe roof, applied within $150^{\circ}$ of the arch, $\mathrm{L}=10 \mathrm{~m}$, circular distance $0.4 \mathrm{~m}$, vertical spacing $6.0 \mathrm{~m}$, extrapolation angle about $18^{\circ} ; \Phi 42$ advanced small pipe, set in the arch $150^{\circ}$ range, $\mathrm{L}=3 \mathrm{~m}$, circumferential spacing of $0.3 \mathrm{~m}$, longitudinal $1.0 \mathrm{~m}$, external insertion angle of $18^{\circ}$. The advanced pipe roof and small pipe are cement-water glass double slurry (water slurry ratio of cement slurry is 1:1), and the grouting pressure is controlled within $0.5 \mathrm{MPa}$. The tunnel was excavated by step method.

\section{NUMERAL CALCULATIONS}

This paper used FLAC3D finite difference software to establish a three-dimensional model. According to SaintVenant's principle, The distance between the horizontal and the lower boundary of the model was set to 3 times the tunnel excavation distance, and the upper boundary was taken to the surface. The overall size of the model was set to be $24 \mathrm{~m}$ long, $56 \mathrm{~m}$ wide, and $40.5 \mathrm{~m}$ high, with a total of 154,399 nodes and 149,568 units, as shown in the Fig.2. The model boundary constraint was to set the front, back, left and right, and the bottom to be the normal displacement constraint, and the top of the model was set to the free surface. According to the engineering geological conditions and mechanical state of the surrounding rock of the tunnel, the Mohr-Coulomb yield criterion was adopted as the

constitutive model of the surrounding rock. At the same time, it is assumed that the surrounding rock was an ideal elasticplastic material, and the surrounding rock was considered as a continuous uniform medium [4].

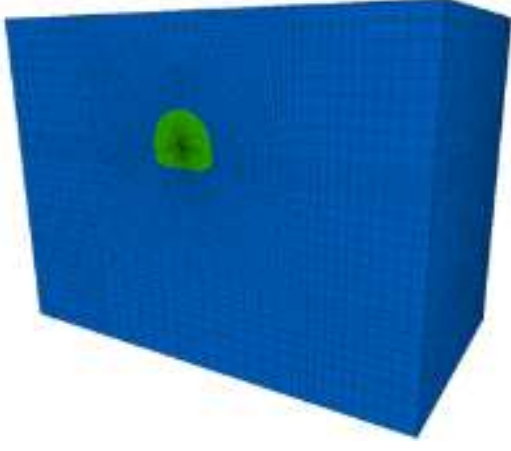

Fig.2 FLAC3D numerical model

The bulk modulus $\mathrm{K}$ and the shear modulus $\mathrm{G}$ of the strata required by numerical simulation can be calculated according to (1).

$$
K=\frac{E}{3(1-2 \mu)}, G=\frac{E}{2(1+\mu)}
$$

where $\mathrm{K}$ is the bulk modulus, $\mathrm{G}$ is the shear modulus, $\mathrm{E}$ is the elastic modulus, and $\mu$ is Poisson's ratio.

In this paper, the tunnel excavation footage is $14 \mathrm{~m}$, and three different case are designed, namely, without support (case 1), pipe roof grouting support (case 2), and advanced small pipe grouting support (case 3). The distribution of stress, strain and plastic zone of surrounding rock under different case is studied. Pipe roof and advance small pipe support are simulated by the beam unit. The advanced support can form uniform, equal thickness and high-strength reinforcement rings in the reinforced area, reinforce the unexcavated surrounding rock and support surrounding rock in the unexcavated area. Therefore, numerical simulations generally use the equivalent enhancement of the reinforcement zone mechanical parameters to simulate the advance support.

For steel pipes filled with cement-water glass double slurry, the elastic modulus is equivalently converted according to (2) [6], 


$$
E_{\mathrm{m}}=\left(E_{1} I_{1}+E_{2} I_{2}\right) /\left(I_{1}+I_{2}\right)
$$

where $E_{m}$ is the equivalent modulus of the grouting steel pipe, E1 is the elastic modulus of the steel pipe, $E_{2}$ is the elastic modulus of the filling slurry in the pipe, $I_{I}$ is the moment of inertia of the steel pipe, $I_{2}$ is the moment of inertia of the section of the filling slurry.

The converted elastic modulus of the grouting reinforcement zone can be calculated according to (3) [11, 12], and its equivalent gravity can be calculated according to (4) [13],

$$
\begin{gathered}
E_{\mathrm{s}}=\mathrm{E}_{0}+\frac{S_{g} E_{g}}{S_{c}} \\
\gamma=\left(A_{1} \gamma_{1}+A_{2} \gamma_{2}\right) /\left(A_{1}+A_{2}\right)
\end{gathered}
$$

where $E_{s}$ is the elastic modulus of the ground after conversion, $E_{g}$ is the elastic modulus of the steel pipe, $\mathrm{Sg}$ is the equivalent cross-sectional area of the steel pipe support, $S_{c}$ is the cross-section of the support section, $\gamma_{1}$ is the severity of the steel pipe, $\gamma_{2}$ is the gravity of the filling slurry in the pipe, $A_{l}$ is the cross-sectional area of the steel pipe, and $A_{2}$ is the cross-sectional area of the filling slurry.

Based on (5) [11], the thickness of grouting reinforcement ring can be calculated,

$$
D_{S}=2\left[R^{2}-\left(\frac{S}{2}\right)^{2}\right]^{\frac{1}{2}}
$$

where $\mathrm{R}$ is the slurry diffusion radius ( $\mathrm{m}), \mathrm{S}$ is the distance between two adjacent grouting holes (m).

The cohesion and internal friction angle of the added solids in the grouting reinforcement range of the surrounding rock can be calculated according to (6) and (7) [12, 14],

$$
\begin{gathered}
c=c_{r}+n S\left(c_{b}-c_{r}\right)+\sigma \tan \varphi \\
f=f_{r}(1-n S)+f_{b} n S
\end{gathered}
$$

where $c$ is the cohesion of the surrounding rock (MPa), $n$ is the arrangement density of the steel pipe (root/m2), $S$ is the cross-sectional area of the steel pipe (m2), $\sigma$ is the extrusion stress produced by the axial action of the steel pipe in the rock mass (MPa). $f$ is the internal friction coefficient of the anchor, $f_{\mathrm{r}}$ is the internal friction coefficient of the surrounding rock, $f_{\mathrm{b}}$ is the internal friction coefficient of the steel pipe.

Based on the above analysis, according to the 'Code for the Construction of Railway Tunnels' (TB2002) and related engineering experience, the physical and mechanical parameters of the supporting structures calculated in this paper are listed in TABLE 2.

\section{RESUlt ANALYSIS}

In this paper, the model surface is flat and the soil layer is homogeneous. There is no tectonic stress except gravity. There is no tunnel bias phenomenon, and the model deformation and stress are symmetrical about the center axis. Therefore, in the analysis of the calculation results, the data of the same side of the axis of symmetry is used as a representative.

The numerical calculation was completed after the tunnel was excavated to $15 \mathrm{~m}$, and the results of the corresponding displacement, stress, and plastic zone distribution were analyzed as follows.

The contour of displacement and stress at a distance of $9 \mathrm{~m}$ from the tunnel face was showed in Fig. 3 and Fig.4. When the advance support is applied, the settlement of the vault decreases obviously, and the settlement of the surrounding rock of the tunnel is effectively suppressed. Furthermore, with the application of advanced support, the stress of the surrounding rock of the vault increases obviously.

Based on the numerical calculation results, the displacement changes in the three case of the tunnel are plotted, including the final settlement of the vault (Fig.5) and the displacement of the haunch (Fig.6). Compared with the case 1 , case 2 and case 3 can effectively control the displacement and deformation of the vault and the haunch. The variation rate of the maximum deformation of the vault in case 2 is $13.0 \%$, and The variation rate of the maximum deformation of haunch is $12.9 \%$. The variation rate of the maximum deformation of the vault in case 3 is $9.24 \%$, and

\begin{tabular}{|c|c|c|c|c|c|c|}
\hline & $\begin{array}{c}\text { Density } \\
\gamma\left(\mathbf{k N} / \mathbf{m}^{3}\right) \\
\end{array}$ & $\begin{array}{c}\text { Elastic modulus } \\
\mathrm{E}(\mathrm{MPa})\end{array}$ & $\begin{array}{c}\text { Poisson's ratio } \\
\mu\end{array}$ & $\begin{array}{c}\text { Friction angle } \\
\varphi\left({ }^{\circ}\right) \\
\end{array}$ & $\begin{array}{c}\text { Cohesion } \\
\text { C(kPa) }\end{array}$ & $\begin{array}{c}\text { Thickness } \\
\text { (m) }\end{array}$ \\
\hline $\begin{array}{l}\text { Long pipe roof grouting } \\
\text { reinforcement area. }\end{array}$ & 25.2 & 175.32 & 0.26 & 35.22 & 83.71 & 45 \\
\hline $\begin{array}{l}\text { Advance small pipe grouting } \\
\text { reinforcement area. }\end{array}$ & 25.0 & 177.96 & 0.26 & 35.16 & 83.59 & 50 \\
\hline
\end{tabular}
The variation rate of the maximum deformation of haunch is $6.31 \%$. It can be seen that compared with the working case 3 , casse2 has a better control effect on the settlement of the vault and the extrusion displacement of the haunch.

TABLE II. PHYSICAL AND MECHANICAL PARAMETERS OF SUPPORT STRUCTURE

The monitoring section was taken $9 \mathrm{~m}$ away from the tunnel face, and the ground settlement caused by tunnel excavation under three working conditions was studied, and the ground settlement curve was plotted (Fig.7). Compared with the case 1 , case 2 and case 3 could effectively control ground settlement. According to the calculation, the maximum ground settlement variation rate for case 2 is $4.45 \%$, while the maximum ground settlement variation rate for case 3 is $3.28 \%$. It was found that the control effect of case 2 on ground settlement was better than case 3 . 


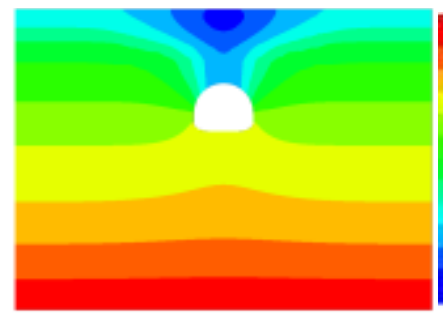

Case 1

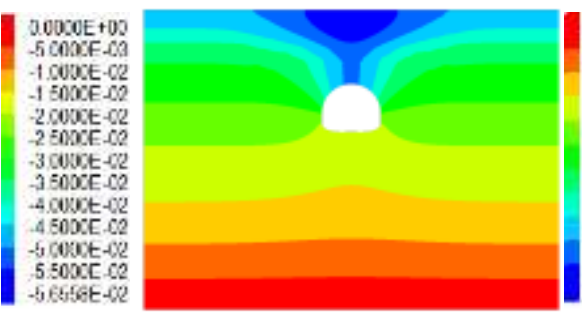

Case 2

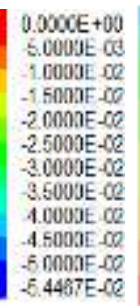

$4497 F-10$

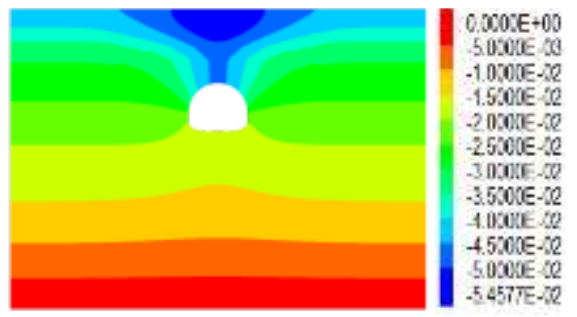

Case 3

Fig. 3 Contour of displacement

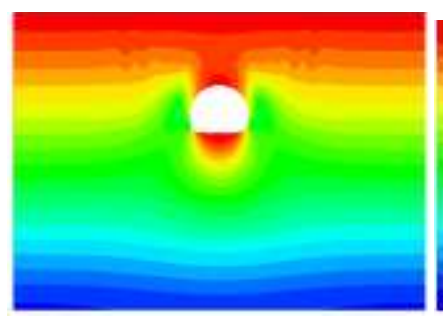

Case 1

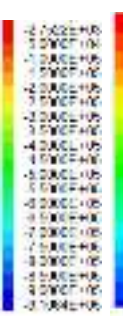

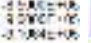

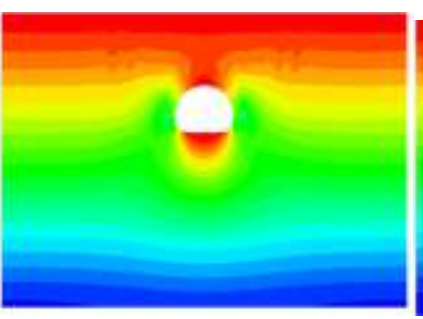

Case 2

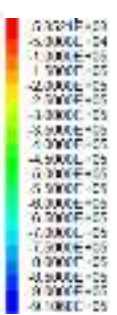

Thit:

Fig.4 Contour of ZZ-stress

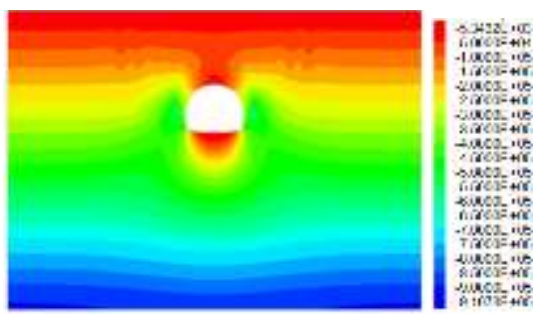

Case 3

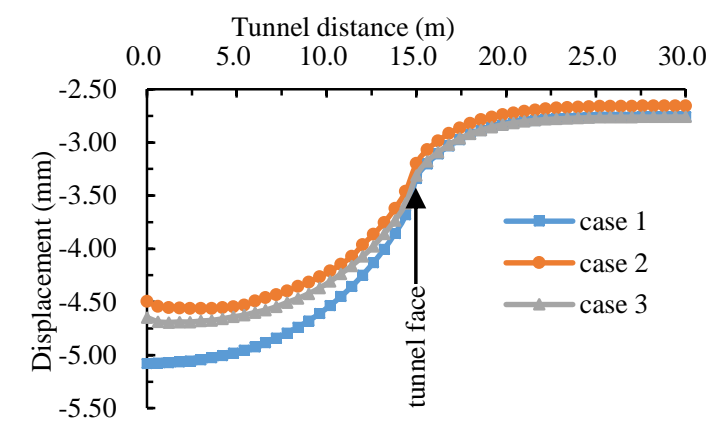

Fig.5 Settlement of tunnel vault

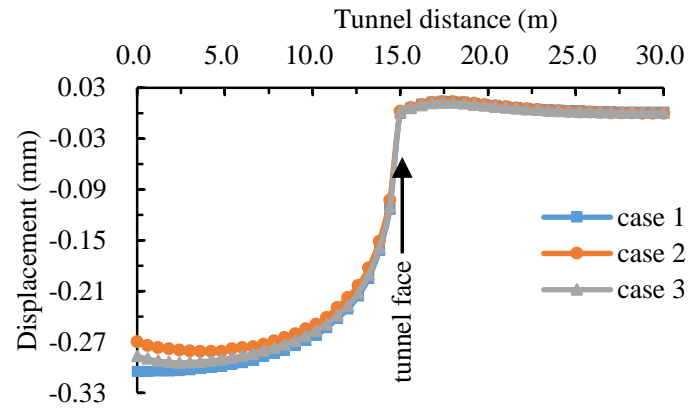

Fig.6 Displacement of tunnel haunch

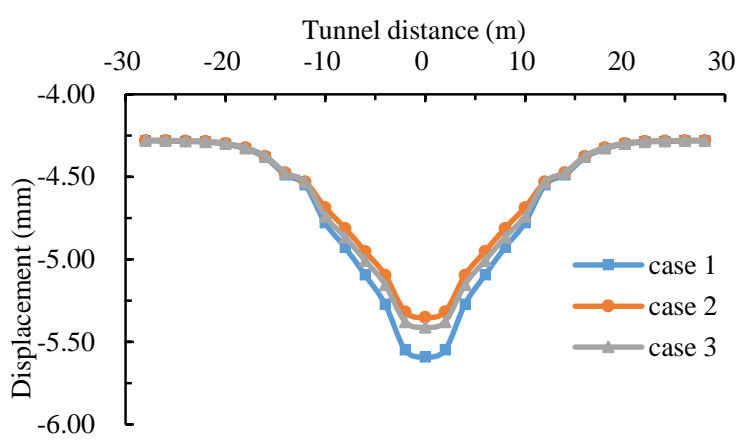

Fig.7 Ground settlement at $9 \mathrm{~m}$ ahead of tunnel face
Meanwhile, this paper also draws a curve of stress changes ahead of the tunnel face, including the vertical stress of the vault (Fig.8) and the horizontal radial stress of the haunch (Fig.9). Compared with the stress distribution of the tunnel vault in case 1 , the stress distribution of the surrounding rock pressure in case 2 and case 3 appears sawtooth undulation. The reason for this phenomenon is the effect of the longitudinal arrangement of the steel tubes in the surrounding rock. According to the vertical stress distribution of the vault and the horizontal radial stress distribution of the haunch, case 2 is better than case 3 and can play a better role in supporting and reinforcing tunnel surrounding rock.

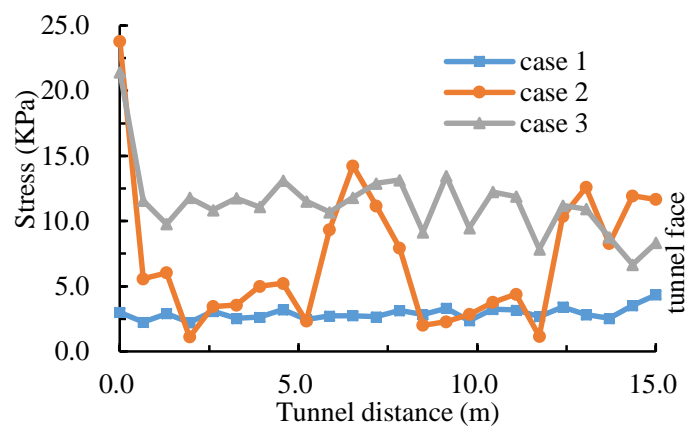

Fig.8 Vertical stress of tunnel vault

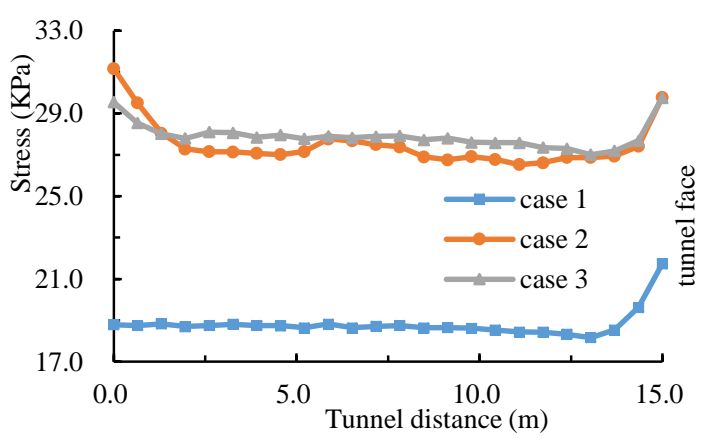

Fig.9 Horizontal radial stress of tunnel haunch 
The plastic zone distribution at the $9 \mathrm{~m}$ position in front of the face is shown in Fig.10. The plastic zone of surrounding rock of the tunnel is $1.0 \sim 3.0 \mathrm{~m}$, and the small pipe support does not pass through the plastic zone in the radial direction. Therefore, it cannot play an anchor role for the broken rock mass. It mainly plays the role of compacting the surrounding rock and increasing the compactness of the surrounding rock. Similarly, pipe roof support can pass through the plastic zone due to its length advantage, so it can not only play a role in compacting the surrounding rock but also can play the role of anchoring the rock mass. Therefore, the distribution range of plastic zone under pipe roof supports is smaller than that of small pipe supports.

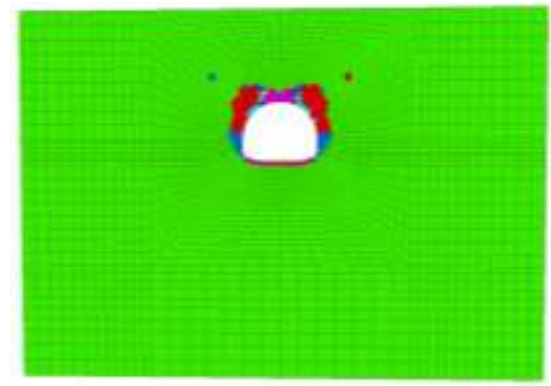

Case 1

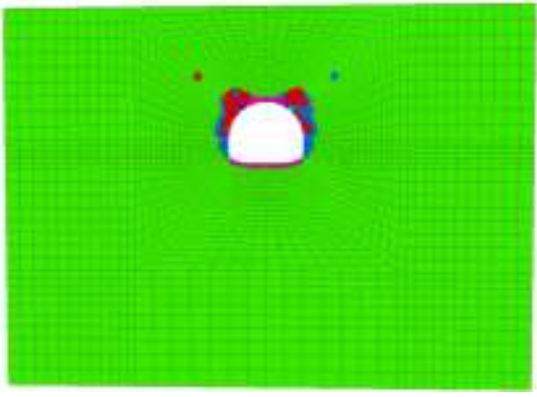

Case 2

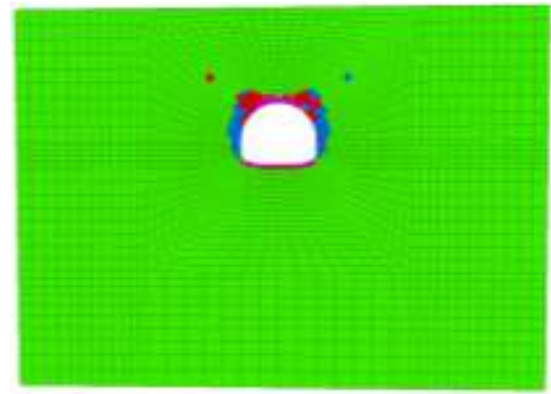

Case 3

Fig.10 Plastic zone distribution at $9 \mathrm{~m}$ ahead of tunnel face

\section{CONCLUSION}

In view of the effect of advanced support measures on the stability of the tunnel surrounding rock, the following conclusions were obtained through calculation and analysis of the three case (without support, pipe grouting support, and advancement of small pipe grouting support).

(1) Compared with working case1, case 2 and case 3 can both support and reinforce the tunnel, and can effectively control the vault, haunch displacement and ground settlement, and reduce the plastic zone distribution during tunnel excavation.
(2) Compared with case 3, case 2 is better at supporting and reinforcing the surrounding rock and controlling the settlement. The steel pipe of pipe roof can pass through the plastic zone, so it can not only compact the surrounding rock like a small pipe, but also can play the role of anchoring the rock mass, thereby effectively reducing the distribution range of the plastic zone.

\section{ACKNOWLEDGMENT}

In this paper, the research was Supported by the FirstRate Discipline Construction Program of Mining Engineering (01LX03303), and Graduate Science and Technology Innovation Program of Shandong University of Science and Technology (SDKDYC180308)

\section{REFERENCES}

[1] Ziaei, Ahad, and K. Ahangari, "The effect of topography on stability of shallow tunnels case study: The diversion and conveyance tunnels of Safa Dam," Transportation Geotechnics, vol. 14, pp. 126-135, 2018.

[2] Yang Xian and Y. Li, "Research of surface settlement for a single arch long-span subway station using the Pipe-roof Pre-construction Method," Tunnelling \& Underground Space Technology, vol. 72, pp. 210-217, 2018.

[3] Fan Honghai, "Numerical calculation and analysis on umbrella pipe and double-row condulet pre-reinforcement supports for timah tasoh tunnel," Subgrade Engineering, vol. 06, pp. 156-159, 2017

[4] Li Shu-cai, Chen Hong-bin, Zhang Chong, "Research on effect of advanced support in silty clay tunnel," Rock and Soil Mechanics, vol. 38, pp. 287-294, 2017.

[5] Xiao J Z, Dai F C, Wei Y Q, et al. "Analysis of mechanical behavior in a pipe roof during excavation of a shallow bias tunnel in loose deposits," Environmental Earth Sciences, vol. 75, 2016.

[6] Tai Qimin, Zhang Dingli, Fang Qian, et al. "Determination of advance supports in tunnel construction under unfavourable rock conditions," Chinese Journal of Rock Mechanics and Engineering, vol. 35, pp. 109-118, 2016.

[7] Zhang Weishe, Wang Weiming, He Guangliang, Lv Xianzhou, "Optimization of supporting scheme for water-rich and weakly consolidated strata tunnel of qingdao metro," Railway Standard Design, vol. 60, pp. 81-87, 2016.

[8] Hong Kairong, Yang Chaohuai, Li Jianhua, "Analysis on impact of advanced support on space deformation of tunnel in soft rock mass," Chinese Journal of Underground Space and Engineering,vol. 10, pp. 429-433, 2014.

[9] Wan Fei, Tan Zhongsheng, Yang Sensen, Ma Dong, "Study on support mechanical behaviour and scheme for shallow buried tunnel in weak surrounding rock with rich water," Engineering Sciences, vol. 16, pp. 45-53, 2014.

[10] Liu Wei, Tang Xiaowu, Gan Penglu, Stravos Savidis, "Soil deformation induced by overlapping tunneling in water-bearing strata," Chinese Journal of Geotechnical Engineering, vol. 35, pp. 1055-1061, 2013.

[11] Liu Tianyu, "Small-lead-tube advanced slip-casting method in tunnel construction and its numerical simulation," Soil Engineering and Foundation, vol. 27, pp. 67-70, 2013.

[12] Zhang Xiangdong, Li Qingwen, Li Guixiu, Gu Xuebing, “Analysis of ground settlement caused by pipe-roof grouting for tunnel construction in shallow soft stratum," Chinese Journal of Rock Mechanics and Engineering,vol. 32, pp. 4091-4097, 2013.

[13] Tang Jinsong, Liu Songyu, Tong Liyuan, "The minimum safe net distance between large span expressway tunnels," China Civil Engineering Journal, vol. 41, pp. 79-84, 2008.

[14] Huo Runke, Li Maoda, Li Jing, Wang Qiang, Yan Jirui, "Numerical simulation and analysis of tunnel construction process of unsymmetrical tunnel in soft rock," Industrial Construction, vol. 45, pp. $95-100,2015$. 